\title{
Breaking the vicious cycle between tumor cell proliferation and bone resorption by chloroquine- loaded and bone-targeted polydopamine nanoparticles
}

\author{
Yitong Wang ${ }^{1,2}$, Hui Chen ${ }^{1}$, Kaili Lin ${ }^{2}$, Ting Ying ${ }^{3}$, Quan Huang ${ }^{4}$, Xiaopan Cai ${ }^{4}$, Jianru Xiao , \\ Qiang Zhang ${ }^{1 *}$ and Yiyun Cheng ${ }^{1,5^{*}}$
}

\begin{abstract}
The vicious cycle between tumor cell proliferation and bone resorption remarkably elevates the progression and metastasis of bone tumors. Here, we fabricated polyethylene glycol-conjugated alendronate-functionalized and chloroquine (CQ)-loaded polydopamine nanoparticles (PPA/ $\mathrm{CQ)}$ for efficient treatment of bone tumors via breaking the vicious cycle. The nanoparticles were efficiently accumulated to the bone tissues, especially the osteolytic lesions around tumors. CQ released from PPA/CQ inhibited osteoclastogenesis via preventing the degradation of tumor necrosis factor (TNF) receptor-associated receptor 3 to attenuate the osteolysis in bone tumors. On the other hand, CQ blocked the autophagy in cancer cells, resulting in improved photothermal killing of cancer cells. Finally, the in vivo experiment revealed that PPA/CQ-associated treatment efficiently inhibited both tumor growth and osteolysis. This work suggests that autophagy inhibition-associated photothermal therapy could be a promising strategy for treating malignant bone tumors.
\end{abstract}

Keywords: targeted nanoparticles, cancer therapy, multifunctional nanoparticles, drug delivery, bone targeting

\section{INTRODUCTION}

Malignant bone tumors frequently occur in clinical practice [1-3]. For instance, More than $60 \%$ of patients who suffer with breast and prostate cancers are diagnosed with bone metastases [4]. The incidence of metastatic bone tumors is continuously increasing due to the prolonged survival of cancer patients [5-7]. Unfortunately, malignant bone tumors are hard to cure $[8,9]$, and the bone resorption-induced skeletal-related events aggravate the malignancy of bone tumors [10-13]. Over $50 \%$ of patients who suffer from malignant bone tumors finally develop complicated complications including bone pain, bone fractures and hypercalcaemia [14,15], which significantly affect the life quality and mortality [16]. However, the clinical relief of these complications causes enormous waste of medical resource and high cost of therapy [17]. Therefore, developing new strategies to treat malignant bone tumors is an urgent issue [18-21].

The communication between tumor cells and bone microenvironment is responsible for the malignancy of bone tumors [22-26]. The tumor cells in bone microenvironment secrete cytokines to stimulate osteoclastogenesis, and in turn the mature osteoclasts resorb bone matrix to release growth factors, resulting in enhanced tumor growth, which forms a vicious cycle between tumor cell proliferation and bone resorption [27]. Blocking

\footnotetext{
${ }^{1}$ Shanghai Key Laboratory of Regulatory Biology, School of Life Sciences, East China Normal University, Shanghai 200241, China

${ }^{2}$ Department of Oral \& Cranio-Maxillofacial Surgery, Shanghai Ninth People's Hospital, College of Stomatology, Shanghai Jiao Tong University School of Medicine; National Clinical Research Center for Oral Diseases; Shanghai Key Laboratory of Stomatology \& Shanghai Research Institute of Stomatology, Shanghai 200011, China

${ }^{3}$ College of Life and Environmental Sciences, Shanghai Normal University, Shanghai 200234, China

${ }^{4}$ Department of Orthopedics Oncology, Changzheng Hospital, the Second Military Medical University, Shanghai 200003, China

${ }^{5}$ South China Advanced Institute for Soft Matter Science and Technology, School of Molecular Science and Engineering, South China University of Technology, Guangzhou 510640, China

* Corresponding authors (emails: qzhang@bio.ecnu.edu.cn (Zhang Q); yycheng@mail.ustc.edu.cn (Cheng Y))
} 
the vicious cycle should improve the treatment of malignant bone tumors [22,24]. Autophagy is a very important pathway to maintain cellular homeostasis [28], and also plays an important role in cancer therapy $[29,30]$. It is proven that nanomaterial-associated photothermal therapy (PTT) can efficiently ablate diverse tumors [31-34], and the inhibition of autophagy by chloroquine (CQ) in tumor cells remarkably enhances the efficiency of photothermal treatment of subcutaneous tumors [35,36]. In addition, PTT can efficiently regress the growth of orthotropic bone tumors [37-39]. These studies suggest that autophagy inhibition-associated PTT could be a potential strategy to suppress malignant bone tumors. On the other hand, autophagy pathway is also involved in the osteoclast differentiation and activation [40]. Autophagy-related gene beclin-1 is upregulated in the monocyte chemotactic protein-1 induced osteoclast differentiation, which however could be inhibited by knocking down Atg7 [41]. Moreover, the tumor necrosis factor receptor associated factors 3 (TRAF3), a negative regulator of osteoclastogenesis, is degraded by autophagy in the receptor activator of nuclear factor-kappa B (NF$\kappa B)$ ligand (RANKL)-induced osteoclast differentiation [42]. CQ could efficiently prevent the degradation of TRAF3 and the activation of osteoclast activation by RANKL. These investigations suggest that autophagy positively affects osteoclast differentiation. Additionally, the autophagy-related proteins like Atg4b, Atg5 and Atg7 are involved in the ruffled border generation and the proteolytic enzyme and proton secretion, thus indicating autophagy acts in osteoclast to regulate the bone resorption [43]. Therefore, the inhibition of autophagy in bone tumors might both improve the photothermal killing of tumor cells and reduce the tumor-associated bone resorption by blocking osteoclastogenesis.

In the present study, we fabricated multifunctional nanoparticles to carry out the bone-targeted and autophagy inhibition-associated photothermal treatment of malignant bone tumors (Scheme 1). The melanin-like polydopamine (PDA) nanoparticles, which have been well studied as photothermal agents and/or drug carriers in previous studies [44-47], were decorated with polyethylene glycol (PEG)-conjugated alendronate (ALN) for bone-targeting [48,49], and were also loaded with CQ for autophagy inhibition [35]. The PEG-ALN-modified PDA (PPA) showed a high affinity to hydroxyapatite (HA) in vitro. Furthermore, the CQ-loaded PPA (PPA/CQ) inhibited the differentiation of osteoclasts. The in vivo experiment revealed that PPA/CQ-associated PTT efficiently inhibited both the bone tumor growth and the progression of osteolysis.

\section{EXPERIMENTAL SECTION}

\section{Materials}

Dopamine hydrochloride was obtained from SigmaAldrich (St. Louis, USA), and ALN from Macklin Biochemical Co., Ltd. (Shanghai, China). Chloroquine phosphate, ammonium hydroxide (28\%-30\%) and Triton X-100 were obtained from Aladdin Reagent Co., Ltd. (Shanghai, China). Methanol and ethanol were purchased from Sinopharm (Shanghai, China). The thiol-PEGsuccinimide ester (SH-PEG-NHS, molecule weight = $1000 \mathrm{Da}$ ) was synthesized by Ponsure Biotechnology (Shanghai, China). Hematoxylin and eosin were obtained from Solarbio (Beijing, China).

\section{Synthesis of SH-PEG-ALN}

In a typical assay, $200 \mathrm{mg}$ of SH-PEG-NHS and $200 \mathrm{mg}$ of ALN were mixed in $10 \mathrm{~mL}$ of deionized (DI) water. After stirring for $24 \mathrm{~h}$, the water in the reaction solution was removed using a rotary evaporator, and then $10 \mathrm{~mL}$ of methanol was added to dissolve the solid with the help of ultrasonication. The undissolved ALN was then removed via centrifugation $\left(15,000 \mathrm{r} \mathrm{min}^{-1}, 15 \mathrm{~min}\right)$. The supernatant was collected and evaporated. The as-obtained $\mathrm{SH}-$ PEG-ALN was washed by using methanol until no precipitation was observed after centrifugation. After purification, SH-PEG-ALN was dried by lyophilization. The matrix-assisted laser desorption/ionization time of flight mass spectrometry (MALDI-TOF MS) was used to analyze the purified product (Fig. S1).

\section{Syntheses of PDA and PPA}

First, PDA was prepared [45]. Generally, ethanol $(8 \mathrm{~mL})$ and DI water $(18 \mathrm{~mL})$ were mixed under magnetic stirring in a vial heated in water bath at $30^{\circ} \mathrm{C}$. Subsequently, $2 \mathrm{~mL}$ of dopamine hydrochloride $\left(50 \mathrm{mg} \mathrm{mL}^{-1}\right)$ was injected into the mixture following the addition of $0.6 \mathrm{~mL}$ ammonium hydroxide $(28 \%-30 \%)$. Finally, the sample was obtained after reaction for $12 \mathrm{~h}$ and purified through centrifugation $\left(15,000 \mathrm{r} \mathrm{min}^{-1}, 15 \mathrm{~min}\right)$. The sample was lyophilized and weighed to determine the concentration of PDA. PPA was subsequently prepared by incubating PDA with SH-PEG-ALN in aqueous solution for $24 \mathrm{~h}$ under magnetic stirring.

\section{Characterization}

The transmission electron microscopy (TEM) images were collected via a Hitachi microscope (HT7700, Japan) 


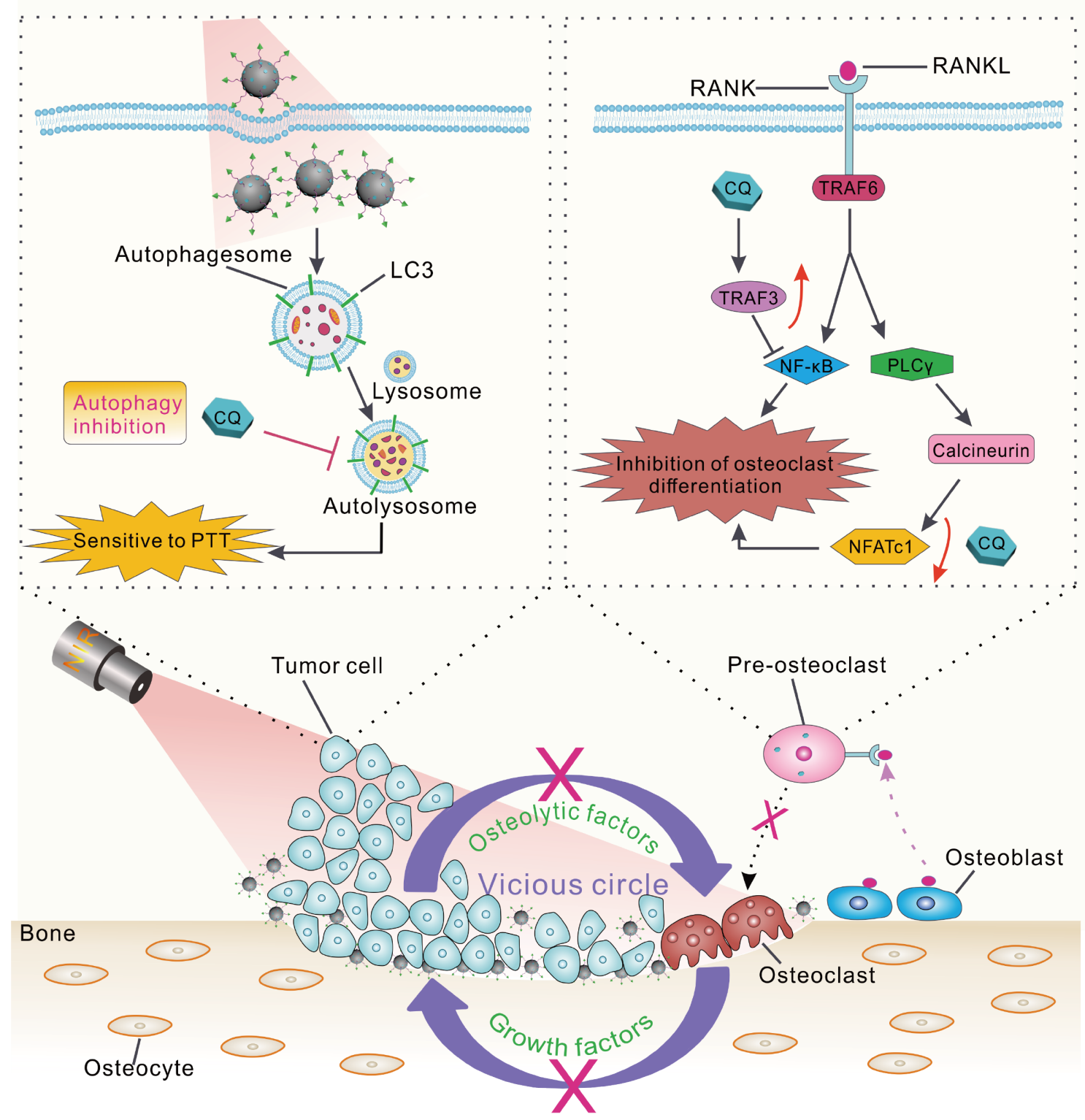

Scheme $1 \mathrm{PPA} / \mathrm{CQ}$-mediated photothermal treatment of malignant bone tumors. CQ released from the nanoparticles blocks autophagy in tumor cells to improve the efficiency of photothermal killing of tumor cells, and inhibits osteoclast differentiation and activation. The PPA/CQ-mediated PTT blocks the vicious cycle between tumor cell proliferation and bone resorption, resulting in efficient tumor regression and osteolysis inhibition.

operated at an acceleration voltage of $100 \mathrm{kV}$. The scanning electron microscopy (SEM) images were taken using a scanning electron microscope (S4800, Hitachi, Japan) operated at $10 \mathrm{kV}$. The Fourier transform infrared (FTIR) spectra were recorded by using a spectrophotometer (Frontier PerkinElmer, USA). The hydrodynamic diameters and zeta potentials of the nanoparticles were measured with Zetasizer Nano ZS90 (Malvern, UK). The ultraviolet-visible (UV-Vis) spectra were recorded by using an UV-Vis spectrometer (Cary60, Agilent Technologies, USA).

\section{Stability of PPA}

In a typical assay, PPA $\left(0.2 \mathrm{mg} \mathrm{mL}^{-1}\right)$ was suspended in $1 \mathrm{~mL}$ of DI water, phosphate buffer saline (PBS) and minimum essential medium (MEM) containing $10 \%$ fetal bovine serum (FBS), respectively. The suspensions were kept undisturbed at room temperature for $7 \mathrm{~d}$. At day 1 
and day 7, the photographs of the suspensions in EP tubes were taken. The hydrodynamic diameters and zeta potentials of the PPA samples were recorded.

\section{Assay to determine the binding affinity of nanoparticles to} HA

Typically, $150 \mu \mathrm{L}$ of PDA or PPA $\left(100 \mu \mathrm{gL}^{-1}\right.$, PDA mass) aqueous solution was incubated with the HA tablets for $24 \mathrm{~h}$. Then, the samples were observed by using SEM after being rinsed and air dried. The samples were also heated by near-infrared (NIR) light $(808 \mathrm{~nm}$, $5.6 \mathrm{~W} \mathrm{~cm}^{-2}$ ) for $5 \mathrm{~min}$.

\section{Drug loading of PPA}

In a typical assay, $10 \mathrm{mg}$ of chloroquine phosphate and ammonium hydroxide $(28 \%-30 \%)$ were mixed in DI water $(1: 6, \mathrm{~mol} / \mathrm{mol})$ under magnetic stirring, and then $50 \mathrm{mg}$ of PPA was added. $24 \mathrm{~h}$ later, the supernatant and PPA/CQ in the solid were separated via centrifugation $\left(15,000 \mathrm{r} \mathrm{min}^{-1}, 10 \mathrm{~min}\right)$. The amount of unloaded CQ was determined via measuring its concentration in the supernatant and the washing water using high performance liquid chromatography (HPLC) at $345 \mathrm{~nm}$ (Fig. S2). The drug loading ratio $=$ (the weight of added drug - the weight of unloaded drug) $\times 100 \% /$ the weight of $\mathrm{PPA} / \mathrm{CQ}$.

\section{NIR irradiation and acidic $\mathrm{pH}$-triggered drug release} In a standard assay, $1 \mathrm{~mL}$ of PPA/CQ $\left(60 \mu \mathrm{g} \mathrm{mL}^{-1}\right.$ for PDA mass, $8.54 \%$ drug loading ratio) in DI water was held in a quartz cuvette, and irradiated by an 808-nm NIR laser at a power density of $3.6 \mathrm{~W} \mathrm{~cm}^{-2}$ for $5,10,15$ and $30 \mathrm{~min}$, respectively. After that, the supernatants were collected via centrifugation $\left(15,000 \mathrm{r} \mathrm{min}^{-1}, 10 \mathrm{~min}\right)$ and then analyzed by HPLC to determine the amount of released CQ.

To assess the drug release of PPA/CQ upon acidic stimulation, $1 \mathrm{~mL}$ of PPA/CQ was loaded in a dialysis bag (molecular weight cut off $=3.5 \mathrm{kDa}$ ) and then immersed in $49 \mathrm{~mL}$ of PBS. The $\mathrm{pH}$ of PBS was adjusted to 7.4 and 6.0 for the $\mathrm{pH}$-responsive release. An aliquot $(0.1 \mathrm{~mL})$ of the PBS solution was collected at different time points, and then analyzed by HPLC to calculate the concentration of released drugs. After each measurement, $0.1 \mathrm{~mL}$ of fresh PBS was added into the PBS solution to keep the volume constant.

\section{Hemolysis test}

In a typical assay, $1 \mathrm{~mL}$ of fresh mouse blood was mixed with $0.1 \mathrm{~mL}$ of sodium heparin solution $\left(1 \mathrm{mg} \mathrm{mL}^{-1}\right)$, and then centrifuged at $2000 \mathrm{r} \mathrm{min}^{-1}$ and $4^{\circ} \mathrm{C}$ for $5 \mathrm{~min}$. The blood cells were collected and rinsed three times with PBS, and then suspended in $5 \mathrm{~mL}$ of PBS for use. The blood cell suspension $(0.5 \mathrm{~mL})$ was mixed with $0.5 \mathrm{~mL}$ of PBS, 1\% Triton X-100, $200 \mu \mathrm{g} \mathrm{mL}^{-1}$ PDA, $200 \mu \mathrm{g} \mathrm{mL}^{-1}$ PPA and $200 \mu \mathrm{g} \mathrm{mL}^{-1} \mathrm{PPA} / \mathrm{CQ}$, respectively. These solutions were incubated at room temperature for $1 \mathrm{~h}$, and then centrifuged at $2000 \mathrm{r} \mathrm{min}^{-1}$ and $4^{\circ} \mathrm{C}$ for $5 \mathrm{~min}$ before photographing.

\section{Cell culture}

The GFP-LC3/HeLa cells stably expressing microtubuleassociated light chain 3 protein fused with green fluorescent protein (GFP-LC3) were cultured in Dulbecco's modified Eagle medium (DMEM). The MDA-MB-231 cells stably expressing luciferase were cultured in MEM. The mouse primary bone marrow mononuclear (BMM) cells were cultured in a-MEM. All the media were purchased from GIBCO, and were added with 10\% FBS (Gemini).

\section{Cytotoxicity of PPA}

In a standard assay, MDA-MB-231 cells in a 96-well plate $\left(1 \times 10^{4}\right.$ cells per well) were treated with different concentrations of PPA $\left(0-500 \mu \mathrm{g} \mathrm{mL}^{-1}\right)$. The cells were then cultured at $37^{\circ} \mathrm{C}$ for $24 \mathrm{~h}$. The cell viability was determined by a standard 3-(4,5-dimethylthiazol-2-yl)-2,5diphenyltetrazolium bromide (MTT) assay.

\section{In vitro photothermal killing of cancer cells}

MDA-MB-231 cells in a 96-well plate $\left(1 \times 10^{4}\right.$ cells per well) were treated with CQ $\left(5.73 \mu \mathrm{g} \mathrm{mL}^{-1}\right), \quad \mathrm{PDA}$ $\left(60 \mu \mathrm{g} \mathrm{mL}^{-1}\right), \quad$ PPA $\left(60 \mu \mathrm{g} \mathrm{mL}^{-1}\right)$ and PPA/CQ (60 $\mu \mathrm{g} \mathrm{mL}^{-1}$ for PDA mass; $5.73 \mu \mathrm{g} \mathrm{mL}^{-1}$ for CQ mass), respectively. The cells were irradiated by NIR light $\left(808 \mathrm{~nm}, 1.0 \mathrm{~W} \mathrm{~cm}^{-2}\right.$ ) for $10 \mathrm{~min}$, and then cultured for $24 \mathrm{~h}$ following the replacement of culture media by fresh ones. Finally, the cell viability was evaluated by a standard MTT assay.

\section{LysoTracker staining assay}

In a standard experiment, GFP-LC3/HeLa cells seeded in $35 \mathrm{~mm}$ dishes $\left(1 \times 10^{5}\right.$ cells per dish $)$ were incubated with CQ $\left(5.73 \mu \mathrm{g} \mathrm{mL}^{-1}\right)$, PDA $\left(60 \mu \mathrm{g} \mathrm{mL}^{-1}\right)$, PPA $\left(60 \mu \mathrm{g} \mathrm{mL}^{-1}\right)$ and PPA/CQ $\left(60 \mu \mathrm{g} \mathrm{mL}^{-1}\right.$ for PDA mass; $5.73 \mu \mathrm{g} \mathrm{mL}^{-1}$ for CQ mass), respectively. After $24 \mathrm{~h}$ incubation, the cells were irradiated by NIR light $\left(808 \mathrm{~nm}, 1.0 \mathrm{~W} \mathrm{~cm}^{-2}\right)$ for $10 \mathrm{~min}$, and then stained by LysoTracker Red (200 $\mathrm{nmol} \mathrm{L}^{-1}$ ) for $20 \mathrm{~min}$. Finally, a confocal microscope (Leica SP5, Germany) was used to examine the cells after 
washing with PBS.

\section{Western blot assay}

GFP-LC3/HeLa cells seeded in a 6 -well plate $\left(1 \times 10^{5}\right.$ cells per well) were incubated with CQ $\left(5.73 \mu \mathrm{g} \mathrm{mL}^{-1}\right)$, PDA $\left(60 \mu \mathrm{g} \mathrm{mL}^{-1}\right), \quad$ PPA $\left(60 \mu \mathrm{g} \mathrm{mL}^{-1}\right)$ and PPA/CQ $\left(60 \mu \mathrm{g} \mathrm{mL}^{-1}\right.$ for PDA mass; $5.73 \mu \mathrm{g} \mathrm{mL}^{-1}$ for CQ mass), respectively. After incubation for $24 \mathrm{~h}$, the cells were harvested and lysed. A routine procedure was then conducted for Western blot assay. Antibodies including antinuclear factor-activated $\mathrm{T}$ cells $\mathrm{cl}$ (anti-NFATc1) and anti-TRAF3 from Abcam (Cambridge, UK), and anti-LC3 and anti-actin antibodies from Cell Signaling Technology (Boston, USA) were incubated with the poly(vinylidene fluoride) (PVDF) membrane at $4^{\circ} \mathrm{C}$ for $12 \mathrm{~h}$. After washing, the membrane was then incubated with Alexa Fluor 680 AffiniPure Goat anti-Rabbit IgG (H+L) (Jackson ImmunoRearch, USA) at room temperature for $2 \mathrm{~h}$. Finally, the membrane was visualized by using enhanced chemoluminescence kit.

\section{Osteoclast differentiation assay}

Mouse primary BMM cells seeded in a 96-well plate $(8,000$ cells per well) were incubated with CQ $\left(5.73 \mu \mathrm{g} \mathrm{mL}^{-1}\right)$, PDA $\left(60 \mu \mathrm{g} \mathrm{mL}^{-1}\right)$, PPA $\left(60 \mu \mathrm{g} \mathrm{mL}^{-1}\right)$ and PPA/CQ $\left(60 \mu \mathrm{g} \mathrm{mL}^{-1}\right.$ for PDA mass; $5.73 \mu \mathrm{g} \mathrm{mL}^{-1}$ for CQ mass), respectively. The culture media were also added with $10 \mathrm{ng} \mathrm{mL}^{-1}$ macrophage colony-stimulating factor (M-CSF) and $50 \mathrm{ng} \mathrm{mL}^{-1}$ RANKL, and were replaced every $2 \mathrm{~d}$ for three times. Finally, the cells were stained with tartrate-resistant acid phosphatase (TRAP) solution (No.387, Sigma). The multinucleated cells $(\geq 3$ nuclei) were counted in each well.

\section{Real-time reverse transcriptase polymerase chain reaction analysis}

The mouse primary BMM cells seeded in 6-well plate $\left(2 \times 10^{4}\right.$ cells per well) were incubated with CQ $\left(5.73 \mu \mathrm{g} \mathrm{mL}^{-1}\right)$, PDA $\left(60 \mu \mathrm{g} \mathrm{mL}^{-1}\right)$, PPA $\left(60 \mu \mathrm{g} \mathrm{mL}^{-1}\right)$ and PPA/CQ $\left(60 \mu \mathrm{g} \mathrm{mL}^{-1}\right.$ for PDA mass; $5.73 \mu \mathrm{g} \mathrm{mL} \mathrm{m}^{-1}$ for CQ mass) for $7 \mathrm{~d}$, respectively. After that, the NFATc1 and TRAF3 mRNA expressing levels in the mouse primary BMM cells were analyzed. The NFATc1 specific primers (NFATc1-forward: 5'-GGAGAGTCCGAGAATCGAGAT-3'; NFATc1-reverse: 5'-TTGCAGCTAGGAAGTACGTCT- ${ }^{\prime}$ ) and TRAF3 specific primers (TRAF3forward: $\quad 5^{\prime}$-TTTTCCCGGCCTTACATCATTC-3'; TRAF3-reverse: 5'-GCTTCTTTGAGGTATTCCGAGAG-3') were used. The $18 \mathrm{~S}$ ribosomal RNA was used as the endogenous reference. A routine procedure was conducted with the use of cDNA Synthesis Kit and SYBR Green Real time PCR Master Mix (TaKaRa, Dalian, China).

\section{In vivo treatment of orthotropic bone tumors}

The experiments were performed according to the $\mathrm{Na}$ tional Institutes of Health guidelines for care and use of laboratory animals and approved by the ethics committee of East China Normal University. BALB/c nude mice (4 weeks old) bought from SLAC Laboratory Animal Co. Ltd. (Shanghai, China) were injected with MDA-MB-231 cells $\left(2 \times 10^{5}\right.$ in $20 \mu \mathrm{L}$ PBS $)$ in the cavum medullare of tibias. An in vivo imaging system (Lumina-II, Caliper Life Sciences, USA) was used to monitor the tumors. The mice grafted with tumors were picked out after two weeks. Twenty-five mice were randomly divided into five groups. Each group of mice were intravenously injected with $100 \mu \mathrm{L}$ of PBS, CQ $\left(2.87 \mathrm{mg} \mathrm{kg}^{-1}\right)$, PPA (30 mg kg${ }^{-1}$, PDA mass) or PPA/CQ (30 $\mathrm{mg} \mathrm{kg}^{-1}$ for PDA mass; $2.87 \mathrm{mg} \mathrm{kg}^{-1}$ for CQ mass; two groups) every four days for three times. NIR irradiation $\left(808 \mathrm{~nm}, 1.0 \mathrm{~W} \mathrm{~cm}{ }^{-2}\right.$, $5 \mathrm{~min}$ ) was subsequently performed on mice injected with PPA and PPA/CQ (one group) 24 and $48 \mathrm{~h}$ after each injection. An infrared thermal camera (Magnity Electronics, China) was used to measure the temperature at the tumors. The tumor growth and the body weights of mice were monitored every day. The tumor-bearing legs were isolated and imaged by a Skyscan 1077 scanner (Antwerp, Belgium), and the data were analyzed by using the CTVox program. The tumor tissues were prepared into slices in paraffin with $4 \mathrm{~mm}$ thickness, and then were analyzed by a terminal deoxynucleotidyl transferase dUTP nick end labeling (TUNEL) assay.

\section{Histological examination}

The major organs including heart, liver, spleen, lungs and kidneys were harvested and fixed in $4 \%$ formalin solution at room temperature for $48 \mathrm{~h}$. The organ tissues were embedded in paraffin blocks and sectioned into slices with a thickness of $4 \mu \mathrm{m}$, and then mounted on glass slides and stained with hematoxylin and eosin (H\&E), respectively.

\section{RESULTS AND DISCUSSION}

PDA has been demonstrated to be an excellent scaffold for both PTT and drug delivery [35-36,50], and is easily fabricated [44,51]. The SH-PEG-ALN was synthesized (Fig. S1), and then decorated on PDA via Michael addition reactions (Fig. 1a) [52,53]. The bisphosphonate ALN are widely used as bone-targeting molecules for targeted 

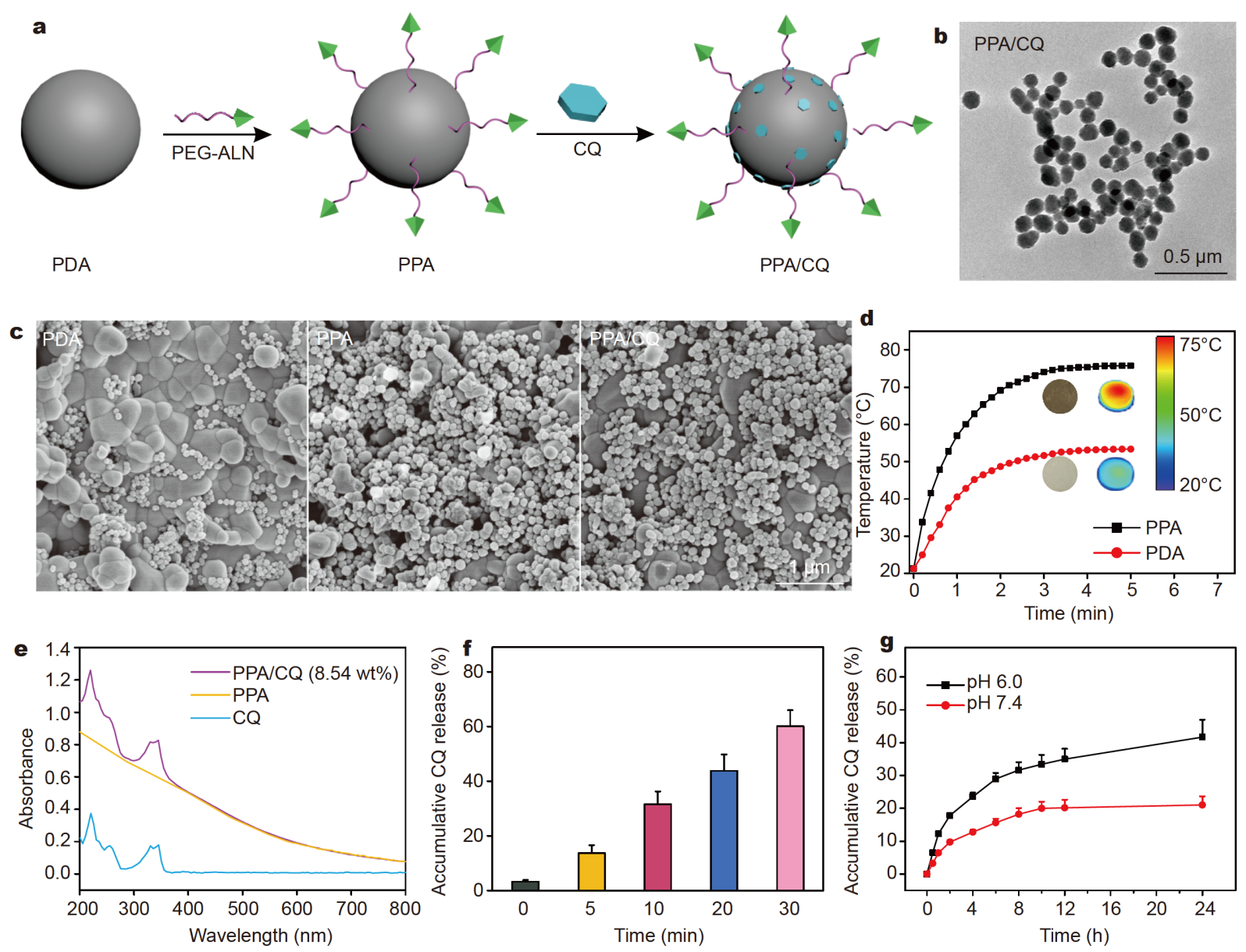

Figure 1 Characterization of the PPA/CQ nanoparticles. (a) Schematic depicts the synthesis of PPA/CQ. (b) TEM image of PPA/CQ. (c) SEM images of HA tablets treated with PDA, PPA and PPA/CQ, respectively. The nanoparticles were incubated with HA tablets in PBS containing $10 \%$ FBS for $12 \mathrm{~h}$. (d) Temperature changes of PDA- and PPA-adsorbed HA tablets during NIR irradiation (5.6 $\mathrm{W} \mathrm{cm}^{-2}, 5 \mathrm{~min}$ ). Insets are photographs of PDAand PPA-adsorbed tablets and their thermographs taken at the end of NIR irradiation. (e) The UV-Vis spectra of PPA and PPA/CQ. The drug loading ratio was $8.54 \mathrm{wt} \%$ for PPA/CQ. (f) NIR irradiation and (g) acidic $\mathrm{pH}$-triggered drug release from PPA/CQ.

delivery of drugs/nanoparticles to bone tissues [48,49]. ALN has two phosphonate groups that are able to chelate calcium ions on HA surfaces, thus resulting in a high binding affinity to bone tissues [48]. The as-synthesized PPA had a spherical shape like PDA, and its average diameter was $107 \pm 12 \mathrm{~nm}$ (Fig. S3). The FTIR spectra reveal that the stretching vibration of $\mathrm{P}-\mathrm{OH}$ groups at $1680 \mathrm{~cm}^{-1}$ was observed in the sample of PPA (Fig. S4), which confirms that SH-PEG-ALN was successfully modified on the surface of PDA. PPA was then incubated in DI water, PBS, and MEM containing 10\% FBS, respectively. After 7-d incubation, PPA was still well suspended in these solutions (Fig. S5a), and its hydrodynamic diameter and zeta potential also had minimal changes (Fig. S5b, c), suggesting that PPA was very stable under the physiological conditions. CQ has been proven to prevent TRAF3 degradation in osteoclast precursors via inhibiting autophagy $[54,55]$, and the increased TRAF3 suppresses the NF- $\kappa B$ signaling and further inhibits the RANKL-induced osteoclastogenesis $[56,57]$. Therefore, CQ was loaded on PPA for autophagy inhibition in this study (Fig. 1a) [58,59]. The obtained PPA/CQ also had a spherical shape, and its average diameter was $114 \pm 16 \mathrm{~nm}$ (Fig. 1b). The hydrodynamic sizes of PDA, PPA and PPA/CQ were determined, which reveal that PPA was larger than PDA (131 versus $118 \mathrm{~nm}$ ) due to the modification of PEG-ALN, and PPA/CQ had the similar sizes with PPA (Fig. S6). To determine the bone-binding capability, PDA, PPA and PPA/CQ were incubated with HA tablets. The SEM images show that 
both PPA and PPA/CQ were more efficiently adsorbed on the HA tablets than PDA (Fig. 1c), which suggests that PPA and PPA/CQ could more tightly bind to bone. The particle-bound tablets were further heated by a NIR laser. As showed in Fig. 1d, the temperature of PPA-adsorbed tablet fast increased to $76^{\circ} \mathrm{C}$, and that of the PDAadsorbed one only increased to $53^{\circ} \mathrm{C}$. The result confirms that PPA had a stronger affinity to the HA tablet. The UV-Vis spectra reveal that CQ was loaded on PPA (Fig. 1e). The loading ratio was determined to be $8.54 \%$ based on the calibration curve (Fig. S2). We further demonstrated that CQ was able to be efficiently released from the nanoparticles upon the stimulation by NIR irradiation and acidic $\mathrm{pH}$ (Fig. 1f, g), which is consistent with the previous reports $[36,58]$.
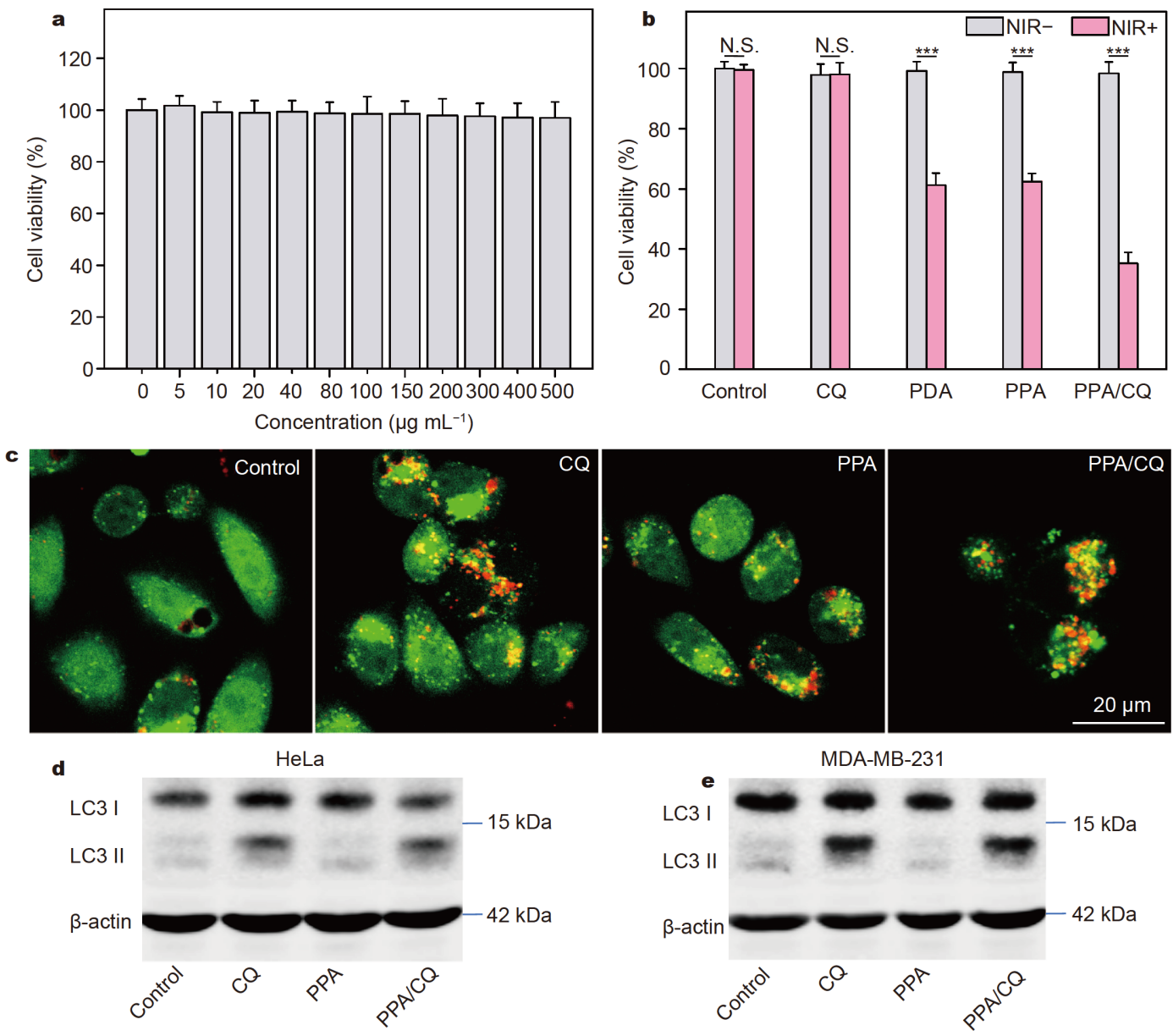

Figure 2 PPA/CQ associated photothermal killing of cancer cells and induced autophagy inhibition in cancer cells. (a) The cytotoxicity of PPA on MDA-MB-231 cells. (b) Autophagy inhibition enhanced the efficiency of photothermal killing of cancer cells. (c) Confocal images of GFP-LC3/HeLa cells treated with PBS (control), CQ, PPA and PPA/CQ for $24 \mathrm{~h}$, and irradiated by an NIR laser $\left(1.0 \mathrm{~W} \mathrm{~cm}^{-2}, 10 \mathrm{~min}\right)$. The cells were stained by LysoTracker Red. (d, e) Western blot images of LC3 conversion in GFP-LC3/HeLa cells (d) and MDA-MB-231 cells (e) treated with PBS (control), CQ, PPA and PPA/CQ for $24 \mathrm{~h}$, and irradiated by an NIR laser $\left(1.0 \mathrm{~W} \mathrm{~cm}^{-2}, 10 \mathrm{~min}\right)$. N.S.: no significance; ${ }^{\star *} p<0.001$ analyzed by student's $t$-test. 
tion in cancer cells [36].

To identify whether PPA/CQ inhibits autophagy in cancer cells, a series of in vitro assays were performed. GFP-LC3/HeLa cells were incubated with CQ, PPA and PPA/CQ, respectively, and then irradiated by NIR light. CQ inhibits autophagy by impairing autophagosome fusion with lysosomes [60]. Therefore, there were more green punctate dots observed in CQ- and PPA/CQ-treated GFP-LC3/HeLa cells compared with the cells without treatment (Fig. 2c). The LysoTracker staining assay reveals that there were more red fluorescence punctate dots co-localizing with the green dots in CQ or PPA/CQtreated GFP-LC3/HeLa cells, indicating that CQ and PPA/CQ halted the degradation of autolysosomes (Fig. 2c). The western blot assay shows that LC3 II protein was significantly increased in GFP-LC3/HeLa cells treated by $\mathrm{CQ}$ or PPA/CQ, which is due to the inhibition of LC3 II protein degradation by CQ (Fig. 2d). Moreover, the Western blot data confirm that CQ and PPA/CQ also inhibited autophagy in MDA-MB-231 cells (Fig. 2e).

The capability of PPA/CQ to inhibit osteoclastogenesis was further evaluated. The mouse primary BMM cells could form the TRAP-stained multinucleated osteoclast in the culture media containing both RANKL and M-CSF [61]. In this case, the mouse primary BMM cells were incubated with PBS, CQ, PDA, PPA and PPA/CQ, respectively. A plenty of multinucleated osteoclasts were formed in PBS, PDA and PPA-incubated mouse primary BMM cells cultured in the presence of M-CSF and RANKL (Fig. 3a). However, there was no osteoclast formed in PBS group without RANKL, and few osteoclasts were detected in CQ or PPA/CQ-treated cells cultured in the presence of M-CSF and RANKL (Fig. 3a). The TRAP-positive multinucleated osteoclasts were
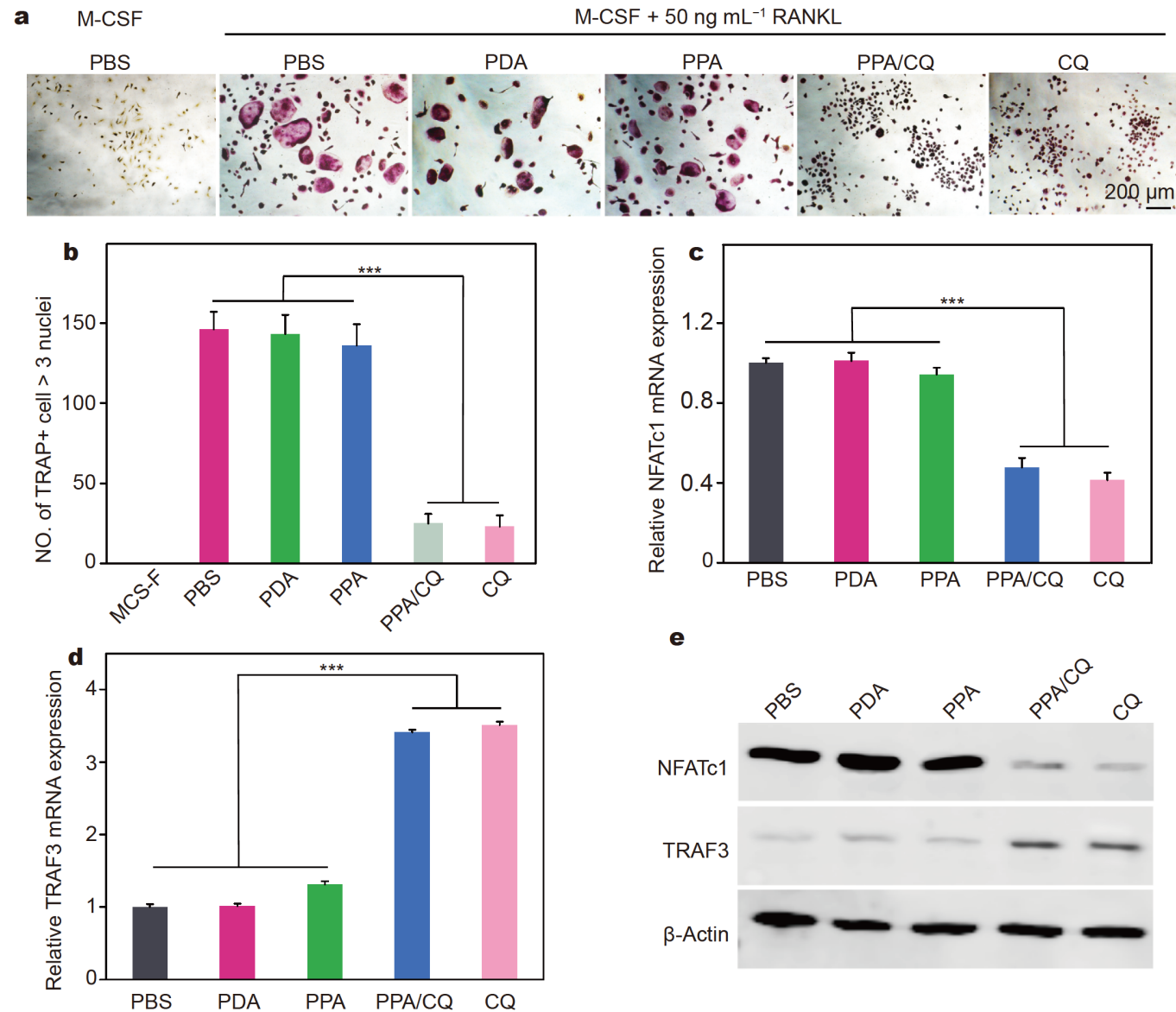

e

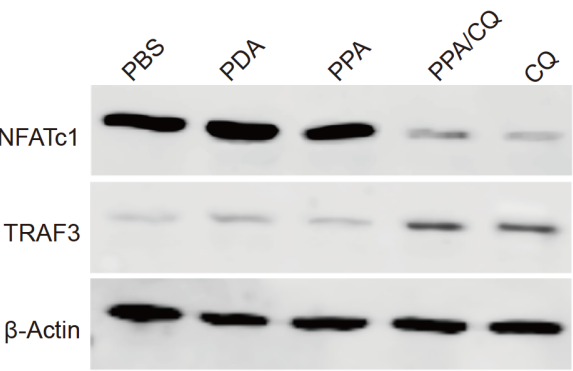

Figure $3 \mathrm{PPA} / \mathrm{CQ}$ inhibits osteoclast differentiation. (a) Optical images of mouse primary BMM cells incubated with PBS, PDA, PPA, PPA/CQ and CQ for $7 \mathrm{~d}$, in the presence of M-CSF and RANKL. The cells were stained by TRAP. (b) Statistical analysis of TRAP-positive multinucleated osteoclast cells in (a). (c) NFATc1 and (d) TRAF3 mRNA expressions in mouse primary BMM cells after the same treatment in (a). (e) Western blot analysis of NFATc1 and TRAF3 proteins in mouse primary BMM cells treated as the same in (a). ${ }^{* *} p<0.001$ analyzed by student's $t$-test. 
quantified after different treatments. The data reveal that over 130 osteoclasts were observed in PBS, PDA and PPA treated mouse primary BMM cells cultured in the presence of M-CSF and RANKL (146 \pm 11 in PBS group with RANKL, $143 \pm 12$ in PDA group, $136 \pm 13$ in PPA group, respectively), while only $25 \pm 6$ and $23 \pm 7$ multinucleated osteoclasts were found in CQ and PPA/CQ treated cells (Fig. 3b). These data suggest that both CQ and CQ loaded on PPA could prevent the osteoclast differentiation, and PDA and PPA had slight influence over the osteoclastogenesis. The osteoclastogenic genes in the mouse primary BMM cells were further quantitatively evaluated. The NFATc1 is requested for osteoclast differentiation $[62,63]$. TRAF3 inhibits RANKL-induced osteoclastogenesis $[64,65]$. The previous study demonstrates that CQ prevents the degradation of TRAF3 to reduce osteoclast formation [44]. The analysis of mRNA expression reveals that NFATc1 was significantly reduced in mouse primary BMM cells incubated with CQ and PPA/CQ (Fig. 3c), and TRAF3 degradation was also obviously prevented (Fig. 3d). The Western blot assay confirms that NFATc1 was down regulated and TRAF3 up regulated in mouse primary BMM cells incubated with $\mathrm{CQ}$ and PPA/CQ (Fig. 3e). All these data suggest that CQ and PPA/CQ could efficiently prevent osteoclastogenesis from mouse primary BMM cells in vitro.

Finally, the in vivo study was performed in an orthotropic bone tumor model [66]. The tumor-grafted mice in five groups were intravenously administrated with PBS, CQ, PPA and PPA/CQ (two groups), respectively (Fig. 4a). The fluorescence images of mice were taken before and after treatment (Fig. $4 \mathrm{~b}$ ). NIR irradiation was subsequently performed on the mice injected with PPA and PPA/CQ (one group) after each injection (Fig. 4c). The temperatures at the tumor-sites were recorded while NIR irradiation. The highest temperature on the tumor was controlled at around $43^{\circ} \mathrm{C}$ (Fig. $4 \mathrm{c}$ ), at which the normal tissues nearby tumor tissues would not be damaged by hyperthermia. The fluorescence images show that the tumors in the PBS, CQ, and PPA/CQ groups rapidly grew during the treatments (Fig. $4 \mathrm{~b}$ ). However, the tumors were efficiently regressed in the PPA+NIR and PPA/CQ+NIR groups (Fig. 4b). Moreover, the average tumor fluorescence intensity was obviously lower in the PPA/CQ+NIR group than that in the PPA+NIR group (Fig. 4d), which suggests that the tumors in PPA/ $\mathrm{CQ}+\mathrm{NIR}$ group were more efficiently regressed. Additionally, the average calf girth of the tumor-bearing legs had no observable increase compared with that of the healthy legs in the PPA/CQ+NIR group, while these of the tumor-bearing legs obviously increased in the other four groups (Fig. 4e). After treatment, the tumors were isolated from the sacrificed mice. As shown in Fig. 4f, g, the tumors were visibly small in the PPA/CQ+NIR group. All these data suggest that the therapeutic efficacy of PTT was significantly enhanced in the presence of CQ. The body weights of mice changed minimally during the therapy (Fig. 4h), and the histological staining reveals that there was no detectable changes in the main organs including heart, liver, spleen, lungs and kidneys after treatment (Fig. S8). These data indicate PPA/CQ had minimal toxicity in vivo. The TUNEL assay reveals that there were more apoptotic tumor cells in the PPA/CQ + NIR groups than in the PPA+NIR group, and meanwhile few apoptotic tumor cells were observed in the PBS, CQ, and PPA/CQ groups (Fig. 4i). The result confirms that autophagy inhibition-associated PTT could more efficiently kill the tumor cells.

The osteolysis in bone tumors could also be alleviated by bone-targeted therapies [67], and thus the tumorbearing tibias was further evaluated by the three-dimensional (3D) micro-computed tomography (micro-CT, Fig. 5a). The bone structures in the PBS group were completely destroyed at the tumor locations, representing as comminuted fracture, while the bone damage was obviously reduced in the CQ and PPA/CQ groups (Fig. 5a), which suggests that CQ functioned for inhibiting osteoclast differentiation and osteolysis. The architecture parameters of the tibias in tumor-bearing legs were further evaluated. As shown in Fig. 5b-e, the bone volume, bone surface, and trabecular numbers (Tb. N.) significantly increased, and the tibia space (Tb. Sp.) obviously decreased in the CQ group compared with those in the PPA/CQ group, suggesting that the bone-targeted nanoparticles improved the blood circulation of CQ and thus enhanced the amount of CQ in the tumors. The individual PTT in the PPA+NIR group efficiently retarded the damage of the tibias (Fig. 5), but the obvious erosion and fracture were still observed at the tumorbearing locations (Fig. 5a). However, the tibias in the PPA/CQ+NIR group had almost intact morphologies (Fig. 5a). The small etched focal points should have existed in the tumors before the treatment (Fig. 5a). The bone architecture parameters were remarkably improved in the PPA/CQ+NIR group (Fig. 5b-e).

Furthermore, the expression profiles of osteoclastogenic genes in the bone tissues were further evaluated. As shown in Fig. 6a, the NFATc1 mRNA expressed at a lower level in the PPA/CQ group than in the PBS or CQ groups, which confirms that the bone-targeted delivery 

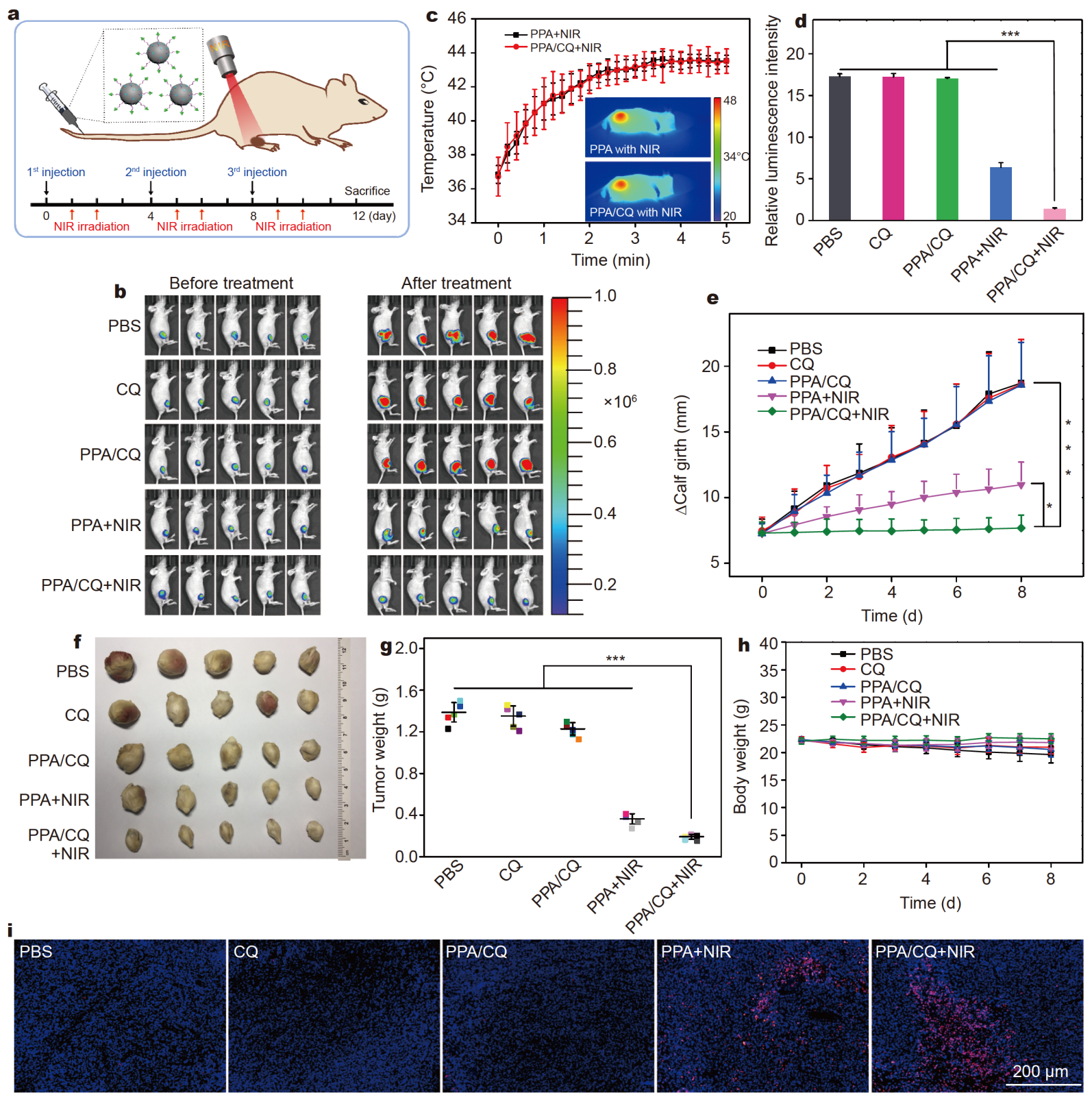

Figure 4 In vivo treatment of orthotropic bone tumors. (a) Scheme illustrates the protocol for PPA/CQ administration and NIR irradiation. (b) Luminescence images of mice before and after treatment. (c) The tumor-site temperature changes recorded during the first NIR irradiation (24 $\mathrm{h}$ after the first injection, $1.0 \mathrm{~W} \mathrm{~cm}^{-2}, 5 \mathrm{~min}$ ). Inset shows the thermographs of mice taken at the end of NIR irradiation. (d) The average luminescence intensities of bone tumors before and after treatment. (e) Average values of the calf girth of tumor bearing leg subtracted by that of healthy leg on the same mouse during the treatment. (f, g) Photographs of bone tumors excised from mice and their average weights. (h) The body weight changes of mice during the treatment. (i) Apoptosis (red) of tumor cells after different treatments analyzed by a TUNEL assay. ${ }^{*} p<0.05$ and ${ }^{* * *} p<0.001$ analyzed by student's $t$-test.

enhanced the concentration of CQ in the bone tumors. PTT only also moderately regressed the expression of NFATc1 mRNA (Fig. 6a), and the autophagy inhibitionassociated PTT by using PPA/CQ more efficiently reduced the expression of NFATc1 mRNA (Fig. 6a). It is also found that TRAF3 were up-regulated in the PPA/CQ, $\mathrm{PPA}+\mathrm{NIR}$ and PPA/CQ+NIR groups (Fig. 6b), indicating both CQ and PTT were able to prevent the degradation of TRAF3. These results demonstrate that the osteoclast differentiation and the osteolysis were efficiently re- 

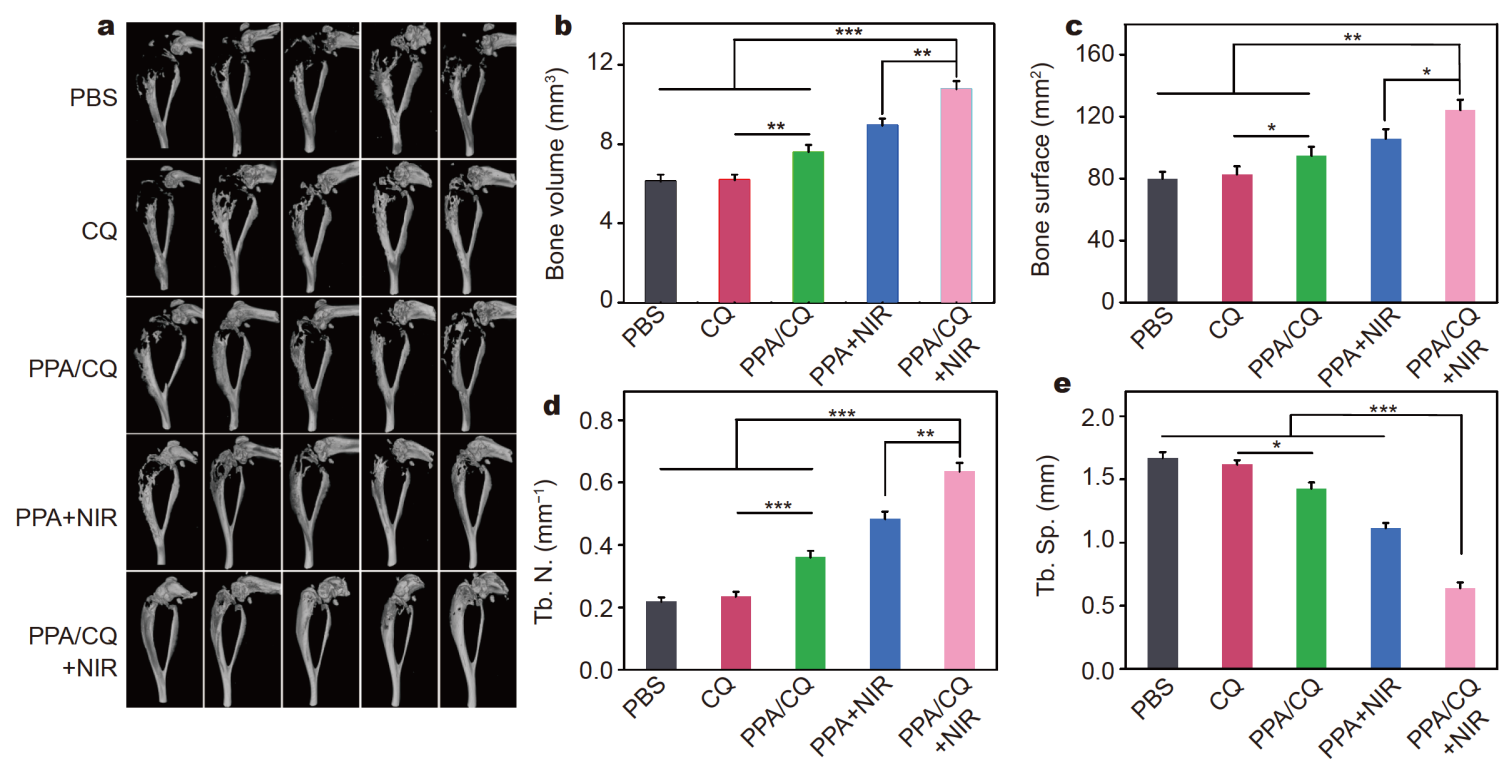

Figure 5 The inhibition of osteolysis by PPA/CQ-mediated treatment. (a) 3D micro-CT reconstruction of the tumor-bearing tibias after treatment. (b-e) Plots of the architecture parameters of bone including bone volume (b), bone surface (c), Tb. N. (d), and Tb. Sp. (e). ${ }^{*} p<0.05,{ }^{* *} p<0.01$ and ${ }^{* * *} p<0.001$ analyzed by student's $t$-test.
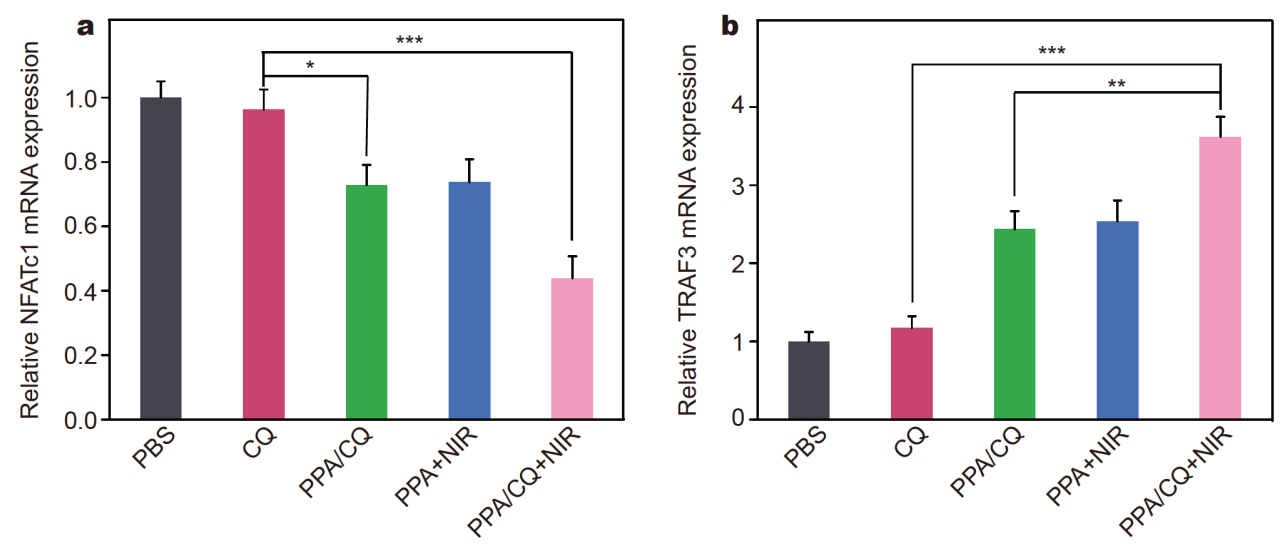

Figure 6 Osteoclast differentiation in bone tumors after treatment. (a) NFATc1 and (b) TRAF3 mRNA expressions in the bone tissues.

gressed.

\section{CONCLUSIONS}

In summary, the autophagy inhibition-associated PTT by using PPA/CQ is capable of regressing malignant bone tumors with high efficiency. CQ inhibited autophagy in cancer cells, resulting in efficiency-enhanced photothermal killing of cancer cells. CQ also inhibited the differentiation and activation of osteoclasts to reduce tumor-associated bone resorption. The combination of autophagy inhibition and PTT by using PPA/CQ suc- cessfully blocked the vicious cycle in bone tumor microenvironment, and thus remarkably enhanced the inhibition of tumor growth and osteolysis at mild photothermal temperature.

Received 7 April 2020; accepted 20 May 2020; published online 21 August 2020

1 Suva LJ, Washam C, Nicholas RW, et al. Bone metastasis: Mechanisms and therapeutic opportunities. Nat Rev Endocrinol, 2011, 7: 208-218

2 Schroeder A, Heller DA, Winslow MM, et al. Treating metastatic 
cancer with nanotechnology. Nat Rev Cancer, 2012, 12: 39-50

3 Mundy GR. Metastasis to bone: Causes, consequences and therapeutic opportunities. Nat Rev Cancer, 2002, 2: 584-593

4 Weilbaecher KN, Guise TA, McCauley LK. Cancer to bone: A fatal attraction. Nat Rev Cancer, 2011, 11: 411-425

5 Hung JY, Horn D, Woodruff K, et al. Colony-stimulating factor 1 potentiates lung cancer bone metastasis. Lab Invest, 2014, 94: 371381

6 Barkin J. How I do it: Managing bone health in patients with prostate cancer. Can J Urol, 2014, 21: 7399-7403

7 Kruger TE, Miller AH, Godwin AK, et al. Bone sialoprotein and osteopontin in bone metastasis of osteotropic cancers. Critical Rev Oncology/Hematology, 2014, 89: 330-341

8 Yin JJ, Pollock CB, Kelly K. Mechanisms of cancer metastasis to the bone. Cell Res, 2005, 15: 57-62

9 Ye L, Kynaston H, Jiang W. Bone metastasis in prostate cancer: Molecular and cellular mechanisms (Review). Int J Mol Med, 2007, 20: $103-111$

10 Swami A, Reagan MR, Basto P, et al. Engineered nanomedicine for myeloma and bone microenvironment targeting. Proc Natl Acad Sci USA, 2014, 111: 10287-10292

11 Meads MB, Hazlehurst LA, Dalton WS. The bone marrow microenvironment as a tumor sanctuary and contributor to drug resistance. Clin Cancer Res, 2008, 14: 2519-2526

$12 \mathrm{Hu}$ Q, Qian C, Sun W, et al. Engineered nanoplatelets for enhanced treatment of multiple myeloma and thrombus. Adv Mater, 2016, 28: 9573-9580

13 Macedo F, Ladeira K, Pinho F, et al. Bone metastases: An overview. Oncol Rev, 2017, 11: 321

14 Rove KO, Crawford ED. Evolution of treatment options for patients with crpc and bone metastases: Bone-targeted agents that go beyond palliation of symptoms to improve overall survival. Oncology, 2011, 25: 1362-1370

15 So A, Chin J, Fleshner N, et al. Management of skeletal-related events in patients with advanced prostate cancer and bone metastases: Incorporating new agents into clinical practice. Can Urol Assoc J, 2012, 6: 465-470

16 Pockett RD, Castellano D, McEwan P, et al. The hospital burden of disease associated with bone metastases and skeletal-related events in patients with breast cancer, lung cancer, or prostate cancer in Spain. Eur J Cancer Care, 2010, 19: 755-760

17 Tipsmark LS, Bünger CE, Wang M, et al. Healthcare costs attributable to the treatment of patients with spinal metastases: A cohort study with up to 8 years follow-up. BMC Cancer, 2015, 15: 354

18 Wang $\mathrm{Y}$, Jiang $\mathrm{C}, \mathrm{He} \mathrm{W}$, et al. Targeted imaging of damaged bone in vivo with gemstone spectral computed tomography. ACS Nano, 2016, 10: 4164-4172

19 Li C, Zhang Y, Chen G, et al. Engineered multifunctional nanomedicine for simultaneous stereotactic chemotherapy and inhibited osteolysis in an orthotopic model of bone metastasis. Adv Mater, 2017, 29: 1605754

20 Sun W, Ge K, Jin Y, et al. Bone-targeted nanoplatform combining zoledronate and photothermal therapy to treat breast cancer bone metastasis. ACS Nano, 2019, 13: 7556-7567

21 Chen C, Li Y, Yu X, et al. Bone-targeting melphalan prodrug with tumor-microenvironment sensitivity: Synthesis, in vitro and in vivo evaluation. Chin Chem Lett, 2018, 29: 1609-1612

22 Croucher PI, McDonald MM, Martin TJ. Bone metastasis: The importance of the neighbourhood. Nat Rev Cancer, 2016, 16: 373-
386

23 Yoneda T, Hiraga T. Crosstalk between cancer cells and bone microenvironment in bone metastasis. Biochem Biophys Res Commun, 2005, 328: 679-687

24 Bussard KM, Gay CV, Mastro AM. The bone microenvironment in metastasis; what is special about bone? Cancer Metastasis Rev, 2008, 27: 41-55

25 Zheng Y, Zhou H, Dunstan CR, et al. The role of the bone microenvironment in skeletal metastasis. J Bone Oncol, 2013, 2: 4757

26 Ye G, Li C, Zhao X, et al. A humanized cancer-bone metastasis mouse model based on silica nanoparticles-incorporated human demineralized bone matrix. J Biomed Nanotechnol, 2019, 15: 2363-2375

27 Waning DL, Guise TA. Molecular mechanisms of bone metastasis and associated muscle weakness. Clin Cancer Res, 2014, 20: 30713077

28 Maes H, Rubio N, Garg AD, et al. Autophagy: Shaping the tumor microenvironment and therapeutic response. Trends Mol Med, 2013, 19: 428-446

29 Levy JMM, Towers CG, Thorburn A. Targeting autophagy in cancer. Nat Rev Cancer, 2017, 17: 528-542

30 Mizushima N, Levine B, Cuervo AM, et al. Autophagy fights disease through cellular self-digestion. Nature, 2008, 451: 1069-1075

31 Chen J, Glaus C, Laforest R, et al. Gold nanocages as photothermal transducers for cancer treatment. Small, 2010, 6: 811-817

32 Zhao R, Han X, Li Y, et al. Photothermal effect enhanced cascadetargeting strategy for improved pancreatic cancer therapy by gold nanoshell@mesoporous silica nanorod. ACS Nano, 2017, 11: 81038113

33 Chen J, Wang D, Xi J, et al. Immuno gold nanocages with tailored optical properties for targeted photothermal destruction of cancer cells. Nano Lett, 2007, 7: 1318-1322

34 Liu Y, Xu J, Liu L, et al. Amorphous manganese dioxide coated polydopamine nanoparticles for acid-sensitive magnetic resonance imaging-guided tumor photothermal therapy. J Biomed Nanotechnol, 2019, 15: 1771-1780

35 Zhang Y, Sha R, Zhang L, et al. Harnessing copper-palladium alloy tetrapod nanoparticle-induced pro-survival autophagy for optimized photothermal therapy of drug-resistant cancer. Nat Commun, 2018, 9: 4236

36 Zhou Z, Yan Y, Hu K, et al. Autophagy inhibition enabled efficient photothermal therapy at a mild temperature. Biomaterials, 2017, 141: $116-124$

37 Zhou Z, Fan T, Yan Y, et al. One stone with two birds: Phytic acidcapped platinum nanoparticles for targeted combination therapy of bone tumors. Biomaterials, 2019, 194: 130-138

38 Yan Y, Gao X, Zhang S, et al. A carboxyl-terminated dendrimer enables osteolytic lesion targeting and photothermal ablation of malignant bone tumors. ACS Appl Mater Interfaces, 2018, 11: 160168

39 Wang C, Cai X, Zhang J, et al. Trifolium-like platinum nanoparticle-mediated photothermal therapy inhibits tumor growth and osteolysis in a bone metastasis model. Small, 2015, 11: 20802086

40 Pierrefite-Carle V, Santucci-Darmanin S, Breuil V, et al. Autophagy in bone: Self-eating to stay in balance. Ageing Res Rev, 2015, 24: 206-217

41 Wang K, Niu J, Kim H, et al. Osteoclast precursor differentiation by MCPIP via oxidative stress, endoplasmic reticulum stress, and 
autophagy. J Mol Cell Biol, 2011, 3: 360-368

42 Xiu Y, Xu H, Zhao C, et al. Chloroquine reduces osteoclastogenesis in murine osteoporosis by preventing TRAF3 degradation. J Clin Invest, 2014, 124: 297-310

43 DeSelm CJ, Miller BC, Zou W, et al. Autophagy proteins regulate the secretory component of osteoclastic bone resorption. Dev Cell, 2011, 21: 966-974

44 Zhou Z, Yan Y, Wang L, et al. Melanin-like nanoparticles decorated with an autophagy-inducing peptide for efficient targeted photothermal therapy. Biomaterials, 2019, 203: 63-72

45 Liu Y, Ai K, Liu J, et al. Dopamine-melanin colloidal nanospheres: An efficient near-infrared photothermal therapeutic agent for in vivo cancer therapy. Adv Mater, 2013, 25: 1353-1359

46 Dong Z, Gong H, Gao M, et al. Polydopamine nanoparticles as a versatile molecular loading platform to enable imaging-guided cancer combination therapy. Theranostics, 2016, 6: 1031-1042

47 Yang $\mathrm{P}$, Zhang S, Chen X, et al. Recent developments in polydopamine fluorescent nanomaterials. Mater Horiz, 2020, 7: 746761

48 Cole LE, Vargo-Gogola T, Roeder RK. Targeted delivery to bone and mineral deposits using bisphosphonate ligands. Adv Drug Deliver Rev, 2016, 99: 12-27

49 Wang X, Miao D, Liang X, et al. Nanocapsules engineered from polyhedral ZIF-8 templates for bone-targeted hydrophobic drug delivery. Biomater Sci, 2017, 5: 658-662

50 Yang $\mathrm{P}$, Zhang $\mathrm{S}$, Zhang $\mathrm{N}$, et al. Tailoring synthetic melanin nanoparticles for enhanced photothermal therapy. ACS Appl Mater Interfaces, 2019, 11: 42671-42679

51 Wang Z, Zou Y, Li Y, et al. Metal-containing polydopamine nanomaterials: Catalysis, energy, and theranostics. Small, 2020, 16: 1907042

52 Wang $\mathrm{X}$, Wang $\mathrm{C}$, Wang $\mathrm{X}$, et al. A polydopamine nanoparticleknotted poly(ethylene glycol) hydrogel for on-demand drug delivery and chemo-photothermal therapy. Chem Mater, 2017, 29: $1370-1376$

53 Wang C, Wang D, Dai T, et al. Skin pigmentation-inspired polydopamine sunscreens. Adv Funct Mater, 2018, 28: 1802127

54 Xue Y, Liang Z, Fu X, et al. IL-17A modulates osteoclast precursors' apoptosis through autophagy-TRAF3 signaling during osteoclastogenesis. Biochem Biophys Res Commun, 2019, 508: 1088-1092

55 Both T, Zillikens MC, Schreuders-Koedam M, et al. Hydroxychloroquine affects bone resorption both in vitro and in vivo. J Cell Physiol, 2018, 233: 1424-1433

56 Yao Z, Lei W, Duan R, et al. RANKL cytokine enhances TNFinduced osteoclastogenesis independently of TNF receptor associated factor (TRAF) 6 by degrading TRAF3 in osteoclast precursors. J Biol Chem, 2017, 292: 10169-10179

57 Boyce BF, Xiu Y, Li J, et al. NF- $\mathrm{kB}-$ mediated regulation of osteoclastogenesis. Endocrinol Metab, 2015, 30: 35-44

58 Gao G, Jiang YW, Jia HR, et al. Near-infrared light-controllable on-demand antibiotics release using thermo-sensitive hydrogelbased drug reservoir for combating bacterial infection. Biomaterials, 2019, 188: 83-95

59 Liu Y, Ai K, Lu L. Polydopamine and its derivative materials: Synthesis and promising applications in energy, environmental, and biomedical fields. Chem Rev, 2014, 114: 5057-5115

60 Klionsky DJ, Abdelmohsen K, Abe A, et al. Guidelines for the use and interpretation of assays for monitoring autophagy (3rd edition). Autophagy, 2016, 12: 1-222
61 Alatalo SL, Halleen JM, Hentunen TA, et al. Rapid screening method for osteoclast differentiation in vitro that measures tartrate-resistant acid phosphatase $5 \mathrm{~b}$ activity secreted into the culture medium. Clin Chem, 2000, 46: 1751-1754

$62 \mathrm{Kim} \mathrm{JH}, \mathrm{Kim}$ N. Regulation of NFATc1 in osteoclast differentiation. J Bone Metab, 2014, 21: 233-241

63 Kim WS, Kim HJ, Lee ZH, et al. Apolipoprotein E inhibits osteoclast differentiation via regulation of c-Fos, NFATc1 and NFкB. Exp Cell Res, 2013, 319: 436-446

64 Yao Z, Xing L, Boyce BF. NF- $\kappa B$ p100 limits TNF-induced bone resorption in mice by a TRAF3-dependent mechanism. J Clin Invest, 2009, 119: 3024-3034

65 Zhao B, Ivashkiv LB. Negative regulation of osteoclastogenesis and bone resorption by cytokines and transcriptional repressors. Arthritis Res Ther, 2011, 13: 234-243

66 Wang C, Sang H, Wang Y, et al. Foe to friend: Supramolecular nanomedicines consisting of natural polyphenols and bortezomib. Nano Lett, 2018, 18: 7045-7051

67 Yin Q, Tang L, Cai K, et al. Pamidronate functionalized nanoconjugates for targeted therapy of focal skeletal malignant osteolysis. Proc Natl Acad Sci USA, 2016, 113: E4601-E4609

Acknowledgements This work was supported by the National Natural Science Foundation of China (21725402, 31871010, 81971735, 81871470 and 81901867), Shanghai Municipal Science and Technology Commission (17XD1401600), the Fok Ying Tong Education Foundation (151036), and Guangdong Innovative and Entrepreneurial Research Team Program (2016ZT06C322). The authors acknowledge the East China Normal University (ECNU) Electron Microscopy Center for the nanoparticle characterization and the ECNU Multifunctional Platform for Innovation (011) for the animal experiments.

Author contributions Wang Y, Zhang Q and Cheng Y designed the research; Wang $\mathrm{Y}$, Chen $\mathrm{H}$ and Ying $\mathrm{T}$ performed the experiments; Huang Q, Cai X and Xiao J constructed the animal model; Wang Y, Lin K, Xiao J, Zhang Q and Cheng Y analyzed the data; Wang Y, Zhang Q and Cheng $\mathrm{Y}$ wrote the paper. All authors contributed to the general discussion.

Conflict of interest The authors declare that they have no conflict of interest.

Supplementary information online version of the paper.

Supporting data are available in the

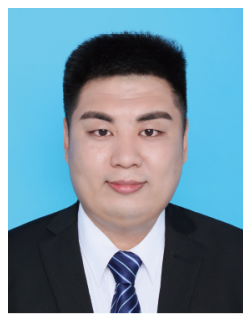

Yitong Wang received his $\mathrm{PhD}$ degree from the East China Normal University in 2018. He is currently working as a postdoctoral fellow at Shanghai Ninth People's Hospital, Shanghai Jiao Tong University School of Medicine. His research interests mainly focus on nanoparticlemediated bone tumor treatment. 


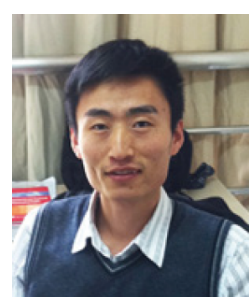

Qiang Zhang is a full professor at the School of Life Sciences, East China Normal University. He received his $\mathrm{BS}$ and $\mathrm{PhD}$ degrees from the University of Science and Technology of China, and was a postdoctoral fellow at Georgia Institute of Technology. His research interests focus on the syntheses of photothermal nanomaterials and their applications in biomedical area.

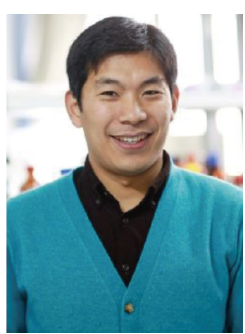

Yiyun Cheng is a full professor at the School of Life Sciences, East China Normal University. He received his $\mathrm{PhD}$ degree from the University of Science and Technology of China and was a postdoctoral fellow at Washington University in St. Louis, MO. His research interests focus on the rational design of polymers for the delivery of biomacromolecules such as DNA, RNA, proteins and peptides.
负载氯喹的骨靶向纳米颗粒打破肿瘤细胞增殖与 骨吸收之间的恶性循环

王伦桐 ${ }^{1,2}$, 陈慧 ${ }^{1}$, 林开利 $^{2}$, 应婷 ${ }^{3}$, 黄权 ${ }^{4}$, 蔡小攀 ${ }^{4}$, 肖建如 ${ }^{4}$, 张强 ${ }^{*}$, 程义云

摘要 肿瘤细胞增殖与骨吸收之间的恶性循环加剧了骨肿瘤的进 展和转移风险. 为此, 我们设计并制备了聚乙二醇-阿仑膦酸钠修饰 的聚多巴胺 (PPA) 纳米粒子, 并在其表面负载自噬抑制剂氯喹 (CQ), 期望利用该治疗载体(PPA/CQ)打破肿瘤细胞增殖与骨吸收 之间的恶性循环, 从而有效地治疗骨肿瘤. 实验证明, PPA/CQ可以 有效地富集到骨组织, 尤其是肿瘤周围的溶骨性病变组织. PPA/ CQ释放的 CQ, 一方面通过抑制肿瘤坏死因子受体相关受体 -3 的降 解, 抑制破骨细胞的生成, 进而减轻骨肿瘤中的骨溶蚀病变; 另一方 面, CQ可以抑制肿瘤细胞的自噬, 从而提高光热治疗对肿瘤细胞的 杀伤效力. 动物实验证明, $\mathrm{PPA} / \mathrm{CQ}$ 介导的联合治疗能有效抑制肿 瘤的生长和骨溶蚀的发生. 该项研究表明, 自噬抑制联合光热疗法 可能成为一种治疗恶性骨肿瘤的有效策略. 